\title{
Ediciones pa que te rí as, otro ejemplo de arte ridículo. Editions pa que te rí as, another example of ridiculous art.
}

\author{
Consuelo Vallejo Delgado \\ Profesora Departamento de Pintura. \\ Universidad de Granada, España. \\ cvallejo@ugr.es \\ http://orcid.org/0000-0002-1883-5693
}

\section{Resumen}

El tema principal de la investigación es el humor en el arte. Estudiamos un ejemplo de edición de arte contemporánea que hemos realizado. Con el título "Pa que te ría as", se presenta un juego de palabras en referencia al error, la ironía y la verdad y su doble. El texto trata estos temas de forma teórica y los relaciona con la obra: un botiquín de medicinas. Los nombres de los medicamentos están cambiados por otras palabras muy similares, que invitan a la reflexión.
Recibido 28/10/2016

Aceptado 07/01/2017
Revisado 05/12/2017

Publicado 01/07/2017
The main topic of research is humor in art. We study an example of contemporary art edition we have done. The title "Pa que te rí as" (meaning pun: "to make you laugh"), talks about laugter, mistake, and truth and its double. The text talks these topics in theory, and practical, through the artist work: a first aid kit medicine. The names of medications are changed for similar words, which invites us to think.

Para citar este artículo

Vallejo Delgado, C. (2017). Ediciones pa que te rí as, otro ejemplo de arte ridículo. Tercio Creciente 13, págs. 8396. https://dx.doi.org/10.17561/rtc.mextra1.5 
Revista de Estudios en Sociedad, Artes y Gestión Cultural

www.terciocreciente.com

http://revistaselectronicas.ujaen.es/index.php/RTC
Monográfico Extraordinario I Julio 2017

Investigación
ISSN: 2340-9096

DOI: $10.17561 /$ rtc.mextra1.5

Palabras clave / Keywords

Arte, humor, ridículo, verdad, error, parafasia.

Art, humor, ridiculous, truth, medicines, mistake, parafasia

Para citar este artículo

Vallejo Delgado, C. (2017). Ediciones pa que te rí as, otro ejemplo de arte ridículo. Tercio Creciente 13, págs. 8396. https://dx.doi.org/10.17561/rtc.mextra1.5 
Revista de Estudios en Sociedad, Artes y Gestión Cultural

ISSN: 2340-9096

DOI: $10.17561 /$ rtc.mextra1.5 www.terciocreciente.com

http://revistaselectronicas.ujaen.es/index.php/RTC
Investigación

1.- Ediciones pa que te rías, otro ejemplo de arte ridículo.

"Ahora puedo decir que el arte es una tontería"

Arthur Rimbaud

\begin{abstract}
"Una vez que el arte dejó de ser mágico, una vez que conquistó y perdió el territorio de lo sagrado sucumbiendo a la seducción de lo laico, una vez que rechazó lo retiniano provocando el divorcio de la mímesis; una vez que hubo recorrido un camino poblado con bisontes, dioses, atletas, héroes, arcángeles, retratos de burgueses, bodegones y paisajes... Fue entonces; el arte se burló del arte" (Vallejo, 2002)
\end{abstract}

Con estas palabras comenzábamos hace más de una década un texto para el IX Congreso Internacional sobre el Discurso Artístico "El humor en todas las épocas y culturas", celebrado en la Universidad de Oviedo. El texto hablaba de cómo el sentido del arte se adscribe al sinsentido, hablaba de Dadá y el Surrealismo, del paso de la emoción romántica al nihilismo, de Freud, Kafka, Camus,..., de la "Mierda de artista" de Manzoni, y del sacrilegio duchampiano del ready made; su cheque -falso"Tzanck", o la burla de la Gioconda con bigote. El texto concluía:

\footnotetext{
"Burlarse de La Gioconda era el pasaporte hacia la nueva identidad de un arte que rechazaba su procedencia áulica y divina, rompiendo con la imagen que encarnaba el ideal artístico, destronándole para humanizarlo. Y quizás Duchamp lo consiguió, porque lo
}

cierto es que, con "L.H.O.O.Q", siglas que leídas fonéticamente significan algo parecido a "ella tiene el culo caliente”, la sonrisa enigmática de La Gioconda, expuesta al ridículo, se hizo vulnerable. Tal vez como la del propio espectador" (Vallejo, 2002).

El interés de la investigación giraba en torno al humor, la ironía, la desacralización del arte, y la impostura. Pasado todo este tiempo, este interés se mantiene. Antes bien, son muchos los estímulos, intelectuales y personales, hasta biográficos, que lo siguen haciendo atractivo; o quizás más aún: necesario. Necesario no sólo a nivel teórico, sino en la práctica artística, como un juego, como una broma de adolescentes, una simple payasada; en definitiva, una tontería pero ¿una tontería muy seria?-. Recomendamos La risa, de Henri Bergson (1973, $1^{\text {a }}$ ed. 1940).

Así nace PA QUE TE RÍ AS cvallejo, una serie de obras que juegan con la palabra y el error, con la verdad y la mentira, al más puro estilo Dadá, rizando el bucle que va de la risa al esperpento, de lo cómico al drama, como en los tiempos remotos del teatro griego, donde los actores iban provistos de máscaras dobles y contrarias que aparecían sucesivamente al voltear la cabeza. Curiosamente, estos sentimientos contrarios duplicados y simultáneos de las máscaras bifaciales (alegría- 
tristeza, bueno-malo, día-noche), no son exclusivos de Grecia, sino que aparecen en prácticamente todas las culturas. Tristes seres contentos, o contentos seres tristes.

Sin embargo, la lógica demuestra que una cosa no puede darse a la vez que su contraria. Tal vez por eso, la verdad, sentenciada por Hegel, ha muerto, y ya sólo podemos vivir en el absurdo. Sí, "se trata de respirar con él”, le confiesa Duchamp a Pierre Cabanne (1984). Convertidos en payasos, cansados de tanta trascendencia, nos queda sólo reconocernos en el disfraz, la carcajada, el gesto divertido que vuelve ligero cada acto, cada pensamiento, cada minuto. Nada nuevo. Busquen en la historia y la antropología. Qué bien lo cuenta Donald Kuspit (2003:226):

\footnotetext{
"Tratar al inhumano mundo ridiculizándolo es hacerlo emocionalmente tolerable. El yo se sostiene por su sentido cómico de las cosas. De hecho, el payaso es un superviviente ingenioso, como el héroe trágico un suicida sin ingenio. El yo que percibe la vida como cómica, incluso hasta el extremo de la farsa perversa, no está traumatizado por el mundo. La comedia es una manera de rodar con las sacudidas del mundo más que de afrontarlas de cara. Los héroes trágicos son brillantes y engreídos, pero predestinados a la perdición y profundamente malogrados, como sugieren sus prematuras muertes. (...) Los antihéroes cómicos saben que nadie es importante para el mundo, y por eso ellos no morirán por él ni se creen nadie, apartándose de todo daño.”
}

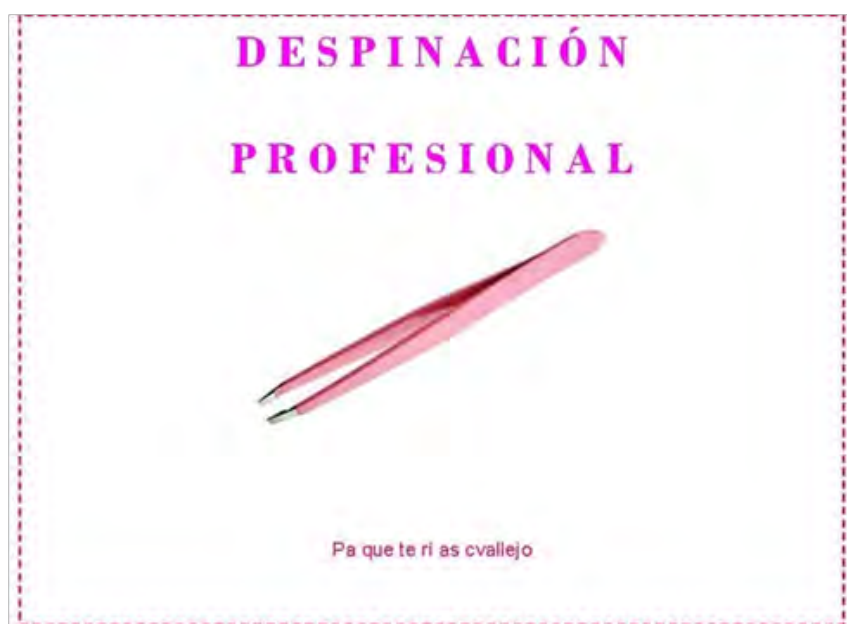

Fig. 1. "Despinación profesional". Serie: Bad-room.

\section{2.- Engaños ópticos y otros trucos. Artificios técnicos e intelectuales.}

El arte es un artificio, siempre lo ha sido. Se requiere técnica e ingenio para producir un cierto engaño en el espectador. Aunque otras veces, no se necesita tanto, ya que el espectador, predispuesto, ve lo que espera ver (Marina, 


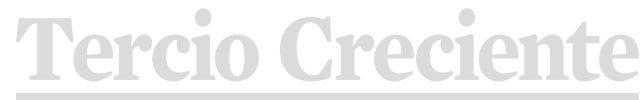

ISSN: 2340-9096

DOI: $10.17561 /$ rtc.mextra1.5
Revista de Estudios en Sociedad, Artes y Gestión Cultural

www.terciocreciente.com http://revistaselectronicas.ujaen.es/index.php/RTC

Investigación

1998), actuando de forma no consciente como cómplice del artista. Sobre el tema, nos remitimos a "El ojo inocente" (1981) de Mark Tansey: una obra pictórica en la que unos personajes le muestran a una vaca una pintura de una vaca. También, a la fábula de Zeuxis y Parrasio, contada por Plinio en el I a. C; aquella en la que las uvas pintadas por Zeuxis le parecen reales al pájaro, y la cortina representada por Parrasio consigue engañar al espectador. Literatura y obras con el tema del engaño en el arte, y sus "simulacros de verdad” (Rivas, 2012) hay mucha, muchísima. También sobre "Lo real y su doble" (Rosset, 1993).

En ciertas épocas históricas el aprendizaje de los trucos del arte para provocar un simulacro ha supuesto un largo camino para el artista, que se iniciaba en los talleres hasta conseguir la suficiente maestría. En el arte actual sucede lo mismo; pensemos, como ejemplo, en complicadas obras de arte y tecnología, que requieren un dominio de lenguajes que no están al alcance de cualquiera. Del lado contrario, también podemos ver casos, algunos ya históricos, de auténtica pereza artística, en los que el autor se ahorra todos los esfuerzos procedimentales y técnicos, incluso aquellas en las que directamente se copia, ¡se copia!. Ejemplos buenos y malos los hay de los dos casos descritos. Dice Pere Sousa (2015:10-11) sobre la autoría de la obra y el plagio:

\footnotetext{
"Hasta no hace muchos años los pintores copiaban a los maestros que a su vez copiaron a los maestros anteriores, la innovación consistía en una sutil diferencia entre el trabajo de un artista y la generación anterior.
}

(...) es cierto que hay que saber seleccionar lo que quieres plagiar, por ejemplo, he plagiado parte de este artículo sobre el plagio y como no soy purista no lo he plagiado directamente incluso he puesto algún trozo de texto entre comillas, cada plagio es diferente, el plagio es un proceso creativo.”

"Parafasias sin remedio" de las "pa que te rí as cvallejo", presenta un artificio sencillo, tanto a nivel de ingenio como procedimental; pura vaguería artística. La obra copia, repite, plagia, se apropia de diseños de cajas y etiquetas de medicinas que conocemos y se comercializan en cualquier farmacia, falseándolas, trucándolas. Pero además, se invita a que cada cual las copie y pueda fabricarse su propia obra, si exclusividad. Como telón de fondo, el reclamo de un arte menos elitista. En la imagen de la portada del álbum imprimible y recortable (Fig. 2), se lee:

“No dejes escapar esta oportunidad! ¡A qué esperas para adquirirlo!

Make yourself: Con este álbum imprimible y recortable, apto para todos los públicos, usted podrá fabricarse, de forma sencilla y barata, un kit completo de parafasias sin remedio como el de la fotografía.

Contiene cajas plegables y etiquetas adhesivas que le serán muy útiles para dar solución a esos problemas comunes que no sabe cómo resolver. 
Gratis. Patentado y distribuido por Pa que te rí as cvallejo.

¡No dejes escapar esta oportunidad! ¡A qué esperas para adquirirlo!

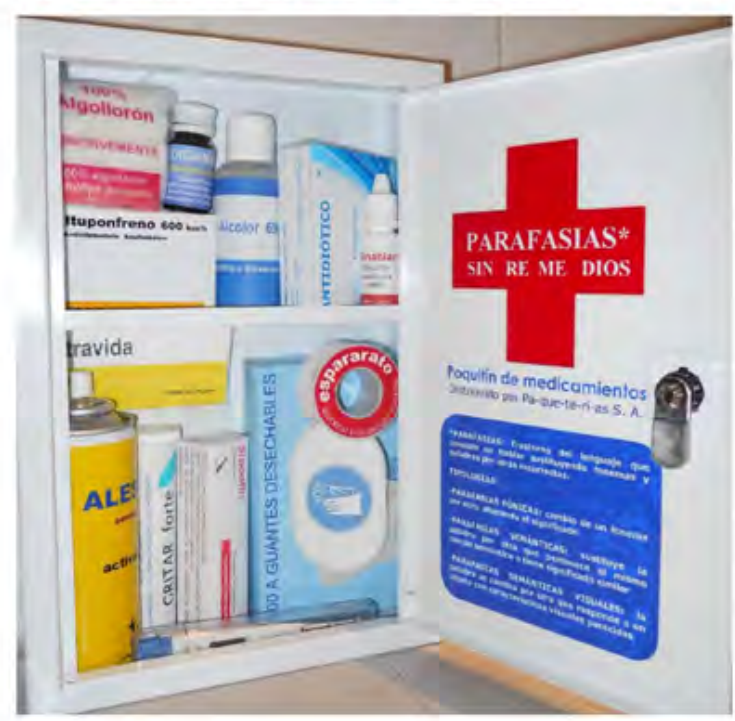

MAKE YOUASEIF: Con este álbum imprimible y recortable, apto para todos los públicos, usted podrá fabricarse, de forma sencilla y barata, un kit completo de parafasias sin remedio como el de la fotografia.

Contiene cajas plegables, y etiquetas adhesivas que le serán muy útiles para dar solución a esos problemas comunes que no sabe cómo resolver.

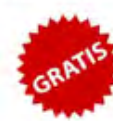

Patentado y distribuido por Pa que te rí as Cvallejo

Fig. 2. Imagen de la portada del álbum imprimible de "Parafasias sin remedios". Versión impresa y archivo en formato pdf para reproducir en impresora doméstica.

\section{3.- Error; horror.}

Equivocarse siempre es un mal síntoma. Dice Ignacio Llamas Labella (1999:87), acerca del error:

"Horror auténtico el error. Horror humano. Enfermedad grave y gratuita la trascendencia, el humano síndrome de fragmentación e indigestión holística por ilusa y abusiva ingestión psíquica de trascendencia.”

El error es un fallo que cometemos cuando decimos o hacemos algo equivocado. Cuenta el dicho que equivocarse es de humanos (y rectificar de sabios); pero lo cierto es que a nadie le gusta (ni lo uno ni lo otro). Cuando se yerra siempre se aduce a la torpeza de la mente o el hacer, y en pocas ocasiones a la voluntad. Erramos sin querer. Siempre.

En el ámbito de la neurología se habla de varios trastornos que producen errores en el lenguaje. Éstos suceden cuando una parte del cerebro está afectada. Existen dos tipos de afasias principales, conocidas en el ámbito de la neurociencia, y recogidas también por Howard Gardner en la cuarta parte de su famosa obra Arte, mente y cerebro, titulada "El deterioro de la mente" (Gardner, 2011). Se trata de la afasia de Broca y la de Wernicke, que provocan estrepitosos efectos en quienes lo padecen, incluso la pérdida absoluta de la capacidad lingüística. Además de éstos, en el campo de la neurología se describen diferentes tipos de Parafasias, trastorno del lenguaje que consiste en hablar sustituyendo fonemas y palabras por otras incorrectas. Desde un punto de vista clínico pueden considerarse como síntoma de una patología mayor. Sin embargo, estos equívocos suelen darse a diario en personas 
www.terciocreciente.com http://revistaselectronicas.ujaen.es/index.php/RTC
Investigación consideradas sanas, muchas veces provocados por un cierto cansancio mental, estrés, etc. que produce el cambio de unas palabras por otras. Se pronuncian, así, palabras involuntarias resultado de pequeños errores cometidos a nivel del significante (una t por una p, o una s por una b, cambios de fonemas, etc. ), dando lugar a un nuevo significado, casi siempre a la vez ingenioso y ridículo. En otras ocasiones, estos errores suceden por aparente azar, como cuando tecleamos un ordenador y sale una palabra equivocada, o cuando el corrector ortográfico del whatsapp provoca que enviemos un disparate: "artistazo/artista zoo".

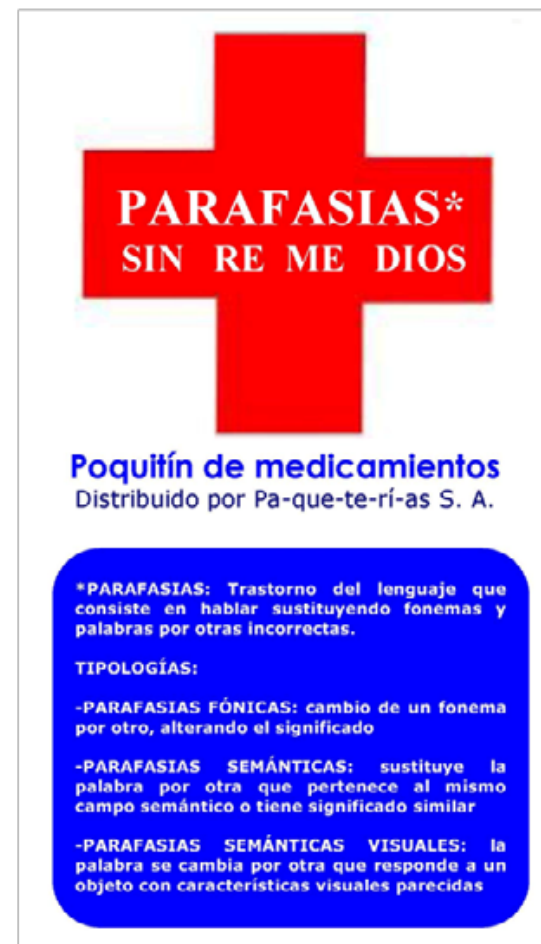

Fig. 3. Imagen interior del botiquín donde pueden leerse los tipos de parafasias más comunes.
A lo largo de la historia del arte, el error ha tenido resultados muy fecundos. También en la ciencia. Hoy se acepta que el conocimiento humano funciona con un tándem que aúna lo racional y lo irracional (aunque aún siga sin valorarse lo suficiente en nuestros sistemas educativos). La superación del positivismo cognitivo supuso aceptar esos orígenes oscuros del conocimiento y la imaginación, como promulgara Bronowsky (1993); el papel del inconsciente para generar conocimiento. El error, a veces sólo aparentemente error, sería la base del pensamiento creativo, como lo demuestran metodologías actuales de divergenciaconvergencia, analogía, etc.

En toda obra de arte hay un mecanismo de sustitución; por ejemplo una pincelada que funciona como rabito de la manzana, un adjetivo que nos evoca una sensación. Se trata de un juego de analogías, en las que el ojo o la mente es capaz de generar un mensaje (en el caso del emisor) o interpretarlo (en el del receptor). El tema de la analogía como método cognitivo ha sido de interés en Foucault, Eco, Barthes, etc., pero ya estaba en la filosofía tomista, o en la explicación del mito. En el caso de la sustitución a nivel de lenguaje, sirva como ejemplo este fragmento de Rayuela, de Julio Cortázar (1993: 395. Citado en Vallejo, 2001) donde la mayoría de palabras, inventadas, no impide que comprendamos el significado, antes bien, lo amplían:

\footnotetext{
"Y sin embargo, era apenas el principio, porque en un momento dado ella se tordulaba los hurgalios, consistiendo en que el aproximara lentamente sus orfelunios. Apenas se entreplumaban, algo como un ulucordio los encrestoriaba, los extrayuxtaba y paramovía, de pronto era el clinón, la esterfurosa convulcante de las mátricas, la jadehollante embocapluvia del orgumio, los esproemios del merpasmo en una sobrehumítica agopausa.“
} 


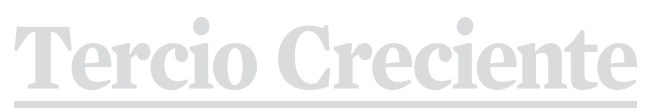

ISSN: 2340-9096

DOI: 10.17561/rtc.mextra1.5
Revista de Estudios en Sociedad, Artes y Gestión Cultural

www.terciocreciente.com

http://revistaselectronicas.ujaen.es/index.php/RTC
Monográfico Extraordinario I Julio 2017

Investigación

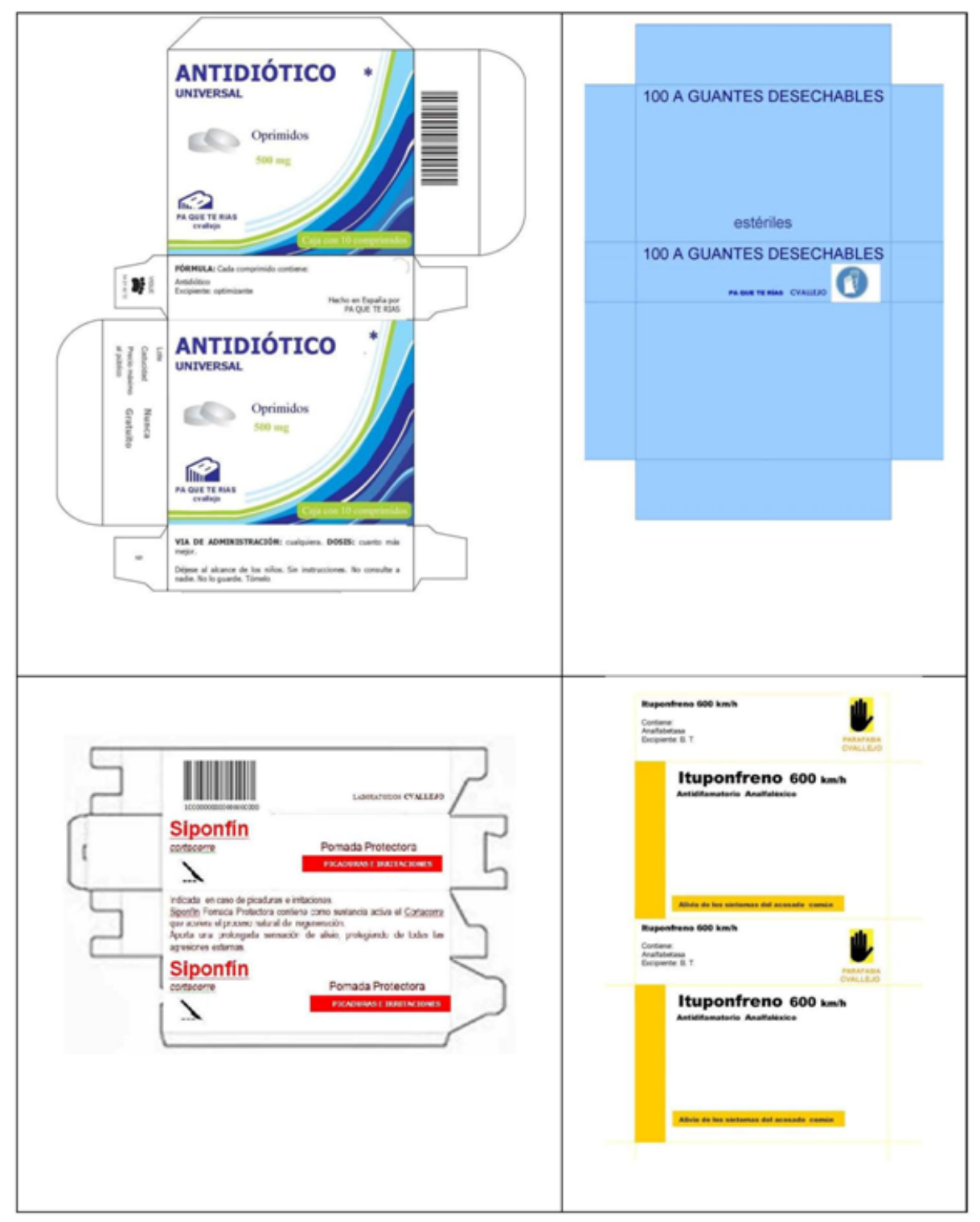


Revista de Estudios en Sociedad, Artes y Gestión Cultural
Monográfico Extraordinario I Julio 2017

Investigación
SSN: $2340-9096$

DOI: $10.17561 /$ rtc.mextra1.5 www.terciocreciente.com

http://revistaselectronicas.ujaen.es/index.php/RTC

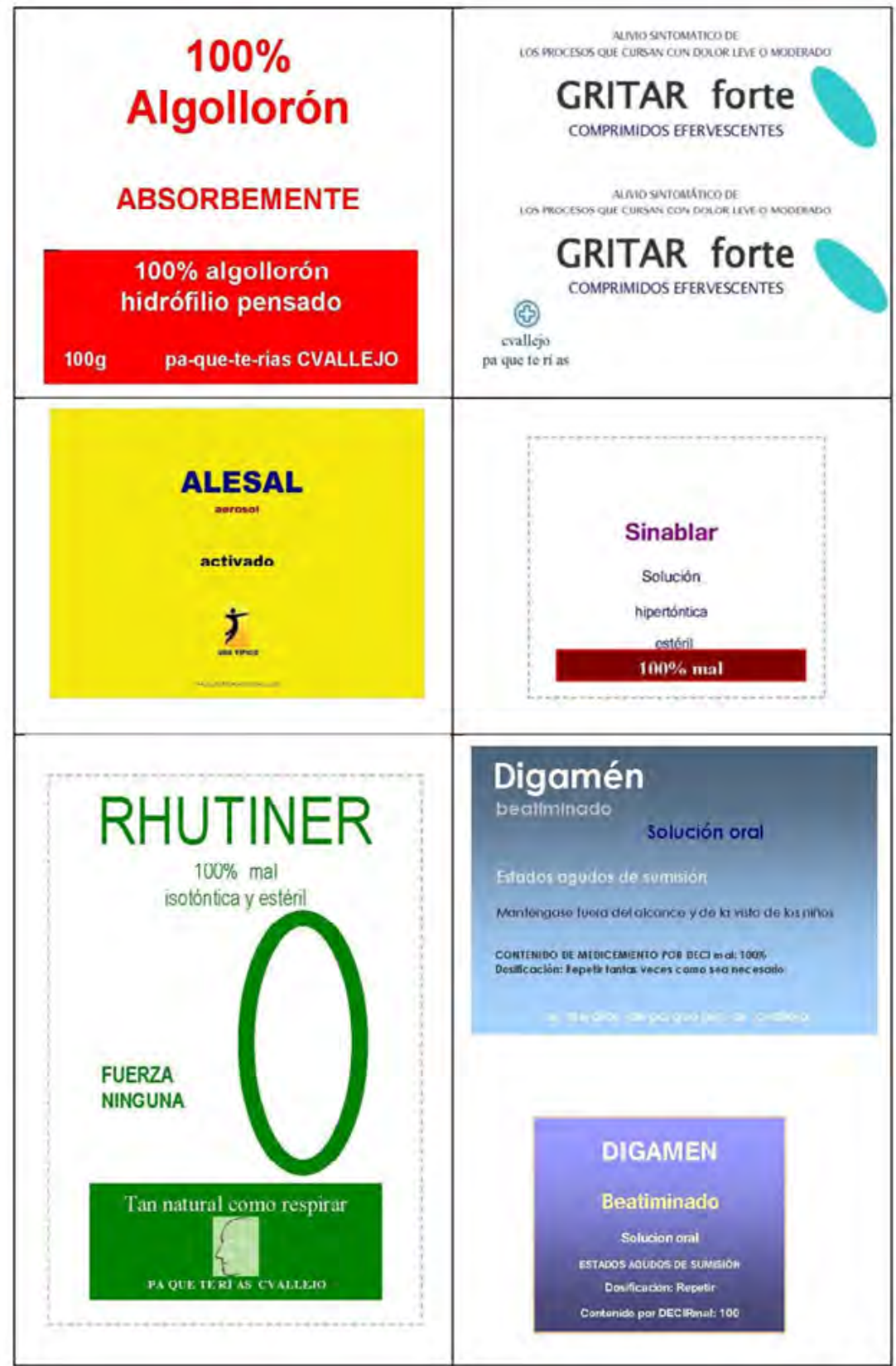

Fig. 5. Etiquetas para intervenir envases y hacer medicamientos. 


\section{4.- Un ejemplo de arte ridículo.}

"El arte no es para tanto", reclama una pieza de la instalación "Fahrenheit" de Luís Costillo (2011). Detrás de la frase, quizás toda una declaración acerca de la falsedad del arte en la sociedad actual. Algunos dicen que fue en el Renacimiento cuando se separó para siempre de la vida y se hizo mercancía. Entonces, el arte comenzó a ser decoro de burgueses, más tarde fue argumento recurrente para la filosofía y la estética, y luego, como sucede hoy tan a menudo, herramienta de lucimiento y postín, promesa de fama y gloria; un arte para "dar el pelotazo". "Vanity, vanity" nos dice el último Rembrandt, abandonado y en la miseria, en el último fotograma de la película homónima (Korda, 1936).

El arte actual, o no ya tan actual, o no sólo el actual, se da cuenta de todo esto, e inaugura "un arte que quiere acabar con el arte, un antiarte que escapa a la reclusión para buscar una conexión con la vida” (Rivas, 2012: 96). Dadà lo supo a tiempo. Aunque quizás este arte, que no quiere ser arte sino verdad, no llegó a perderse nunca. Hay ejemplos que andan extraviados; desacordes estilísticos o conceptuales con la moda del momento.

Hoy parece que el arte, los artistas, perdidos en la propia definición estética y conceptual, ya no saben qué pensar, qué hacer. Así que, aparentemente (o no tan aparentemente) mienten -mentimos- de mil maneras; con lenguajes, materiales, y discursos diferentes. Hemos hablado otras veces de la "indistinción morfológica del arte y la falta de exclusividad de la experiencia estética”. La impostura está servida. Pero, además, tan de mentira o de verdad, tan ridículo a veces, es hacer una obra posmoderna hecha de mentirijilla o para estar al día, como aferrarse a obras románticas y trascendentes con las que acostumbramos a expresarnos. La vergüenza de nuestro yo expuesto es idéntica, o por lo menos, una siente el mismo pudor (acepten la intromisión subjetiva y emocional en un texto científico).

Estos argumentos sirven de leit motiv de la obra "medicamientos" de las "pa que te rí as cvallejo": hacer un disparate, una obra ridícula, un plagio a medias, una tontería con poco ingenio. Leo hoy mismo en un periódico el pequeño texto de Fernando Castro Flórez (ABC, 24-10-2016), titulado "El arte de la mentirijilla consparanoica", donde dice: "La estrategia irónica está sobadísima y, a pesar de ello, surgen algunas obras capaces de desconcertarnos como “Operación Palace”, de Jordi Evole, que funciona como uno de los mejores documentos (sintomatológicos) de la época consparanoica.”

En el caso de las "pa que te rí as”, el funcionamiento es más débil, se reconoce "sobado", pero eficaz. Ciertamente, este botiquín tiene otros porqués; algunos tan privados que no merecería la pena exponerlos (algo de terapia hay), otros tan poco conscientes que se nos escapan, y algunos más, inconsistentes y absurdos. Otra obra innecesaria.

\section{5.- Conclusiones. "Para qué el arte"}

Nos apropiamos aquí del título del libro de Marián López Fdz. Cao (2015): "Para qué el arte", bien hilado y muy recomendable, fiel al mensaje que propone, y perfectamente sintetizado en el subtítulo "Reflexiones en torno al arte y su educación en tiempos de crisis”. Y reflexiono:

¿Quién puede creer-querer ya un Arte (con mayúsculas) exclusivo, siempre nuevo y atento servidor del mercado? ¿Quién puede querer ya un arte que se mide siempre por el éxito? -Qué incómodo, qué esclavitud, qué cansancio-. 
Revista de Estudios en Sociedad, Artes y Gestión Cultural

www.terciocreciente.com http://revistaselectronicas.ujaen.es/index.php/RTC
Julio 2017

Investigación
Aquellos que renunciaron (renunciamos) a estar al último grito en arte -perdón, quiero decir en Arte-, sin perder el curso natural de un proceso histórico de evolución cognitiva, tienen la ventaja de la libertad. La creatividad puede ser cualquier cosa, también ella y su contraria.

Puede que todavía quede la posibilidad de un arte que se haga para vivir, para ir tirando día a día, "para salvar al mundo" -nos atrevimos a decir una vez. ¡Qué exageración!; o no.

Las obras de este arte, de este arte inútil (aprovecho para recomendar La utilidad de lo inútil de Ordine), acabarán en bolsas de basura cuando nos vayamos para siempre; un día después, un mes, o como mucho algunos años más tarde. Desaparecen. Pero queremos creer que son las que, sin embargo, permanecerán, invisibles y eternas, en la enseñanza de los otros; guardadas en esos trasteros que no son los de los museos y las galerías (necesarios también), sino los del alma. Puede que haya un arte que sólo -¿sólo?- ayuda a vivir. No lo olviden.

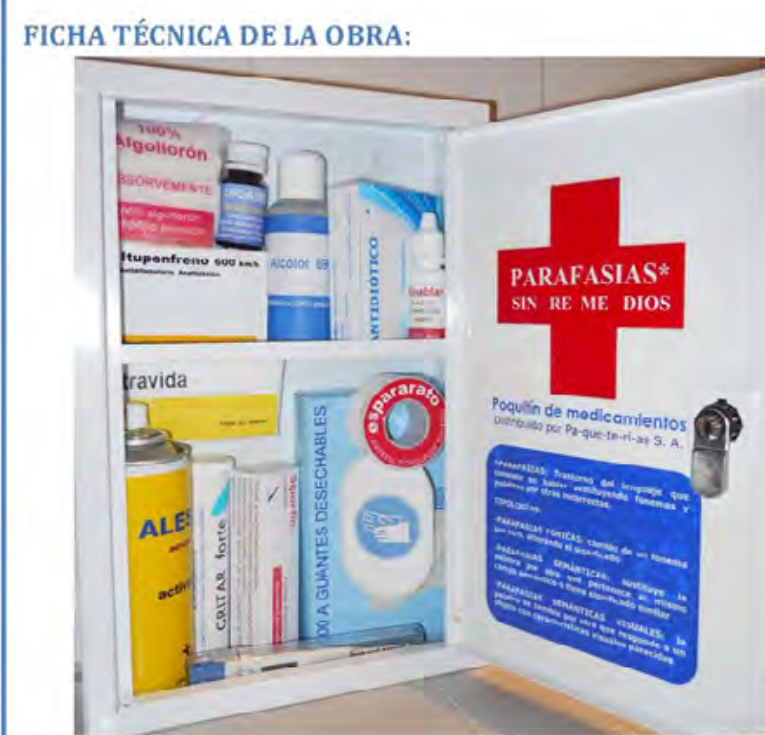

Serie: $B A D-R O O M$

Obra: Parafasias sin remedios

Materlales: diversos envases de medicinas intervenidos con etiquetas y cajas fabricadas a modo de packaging en botiquín metálico.

Medidas: $21 \times 29 \times 8 \mathrm{cms}$

Fabricado y distribuido por: Pa que te rí as cvallejo

DESCRIPCIÓN: "Parafasias sin remedios" hace referencia a la necesidad de sanar los recuerdos, las huellas que quedan en la memoria, las palabras como códigos de los roles impuestos. La Parafasia es un trastorno mental que cambia unas palabras por otras. En esta obra las palabras cambiadas juegan con el error, con la percepción débil, con la impostura. El espectador las descubre, encontrando en ellas la contradicción de su propia sonrisa.

CONTIENE: "Aguantes desechables" "Sinablar. Solución hipertóntica estéril $100 \%$ mal", "Miotravida. oprimidos", "Algollorón absorbemente" "Gritar forte" "Siponfin cortacorre pomada protectora picaduras $e$ irritaciones", "Antidiótico" "Ituponfreno $600 \mathrm{~km} / \mathrm{h}$ ", "Digamén beatiminado", "Tristómetro" "Pinzas de despinación profesional", etc. 


\author{
Investigación
}

\section{Referencias}

Alonso, Jesús (Reportaje) Todos los libros y Fahrenheit de Luís Costillo. Programa documental "La aventura del saber" TVE2,

Recuperado en:https://www.youtube.com/watch?v=SAF3aakJTEM

Bergson, Henri (1973) La risa. Ensayo sobre la significación de lo cómico. Madrid: Espasa Calpe.

Bronowski, Jacob (1993) Los orígenes del conocimiento y la imaginación. Barcelona: Editorial Gedisa.

Cabanne, Pierre (1984) Conversaciones con Marcel Duchamp. Barcelona: Anagrama.

Gardner Howard (2011) Arte, mente y cerebro. Una aproximación cognitiva a la creatividad. Barcelona: Paidós.

Castro Flórez, Fernando (24 de octubre 2016) "El arte de la mentirijilla consparanoica”, ABC. Recuperado en:www. abc. es

Korda, Alexander (Director) (1936). Rembrandt. (Película cinematográfica). Reino Unido: Metro Goldwyn Mayer.

Kluger Jeffrey (2009). Simplejidad. Por qué las cosas simples acaban siendo complejas y cómo las cosas complejas pueden ser simples. Barcelona: Ariel.

Kuspit, Donald (2003) Signos de psique en el arte moderno y posmoderno. Madrid: Akal.

López Fdz. Cao, Marián (2015) Para qué el arte. Reflexiones en torno al arte y su educación en tiempos de crisis. Madrid: Fundamentos.

Llamas Labella, Ignacio (1999) Ser y no ser. Teoría de la idoneidad del conocimiento. Granada: Asociación Cultural EDS/ TAT.

Marina, José Antonio (1998). Teoría de la inteligencia creadora. Barcelona: Anagrama.

Ordine, Nuccio (2013) La utilidad de lo inútil. Barcelona: Manifiesto Acantilado.

Rivas, Eugenio (2012) Simulacros de verdad. Absurdo e ironía en el arte y el pensamiento de la posmodernidad. Granada: Tesis Doctoral Universidad de Granada.

Rosset, Clement (1993) Lo real y su doble. Ensayo sobre la ilusión. Barcelona: Tusquets. 
Revista de Estudios en Sociedad, Artes y Gestión Cultural

www.terciocreciente.com

http://revistaselectronicas.ujaen.es/index.php/RTC
Monográfico Extraordinario I Julio 2017

Investigación

Sousa, Pere (2015) “El autor el autor...”. En Antón, José Emilio; Sanz Montero: Ángel. El libro de los libros de artista. Sestao, Bilbao: Editorial La Única Puerta a la Izquierda. 10-12.

Vallejo Delgado, Consuelo (2001) Arte y Ciencia. Analogía y anacronismo desde el pensamiento actual. Tesis Doctoral. Granada: Universidad de Granada.

Vallejo Delgado, Consuelo (2002). “L. H. O. O. Q. El arte que se burló del arte”. En Caramé Lage, J. L; et. al (edit.) IX Congreso Internacional sobre el Discurso Artístico "El humor en todas las épocas y culturas". Oviedo: Universidad de Oviedo. 


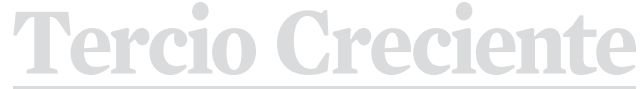

ISSN: 2340-9096

DOI: 10.17561/rtc.mextra1.5
Revista de Estudios en Sociedad,

Artes y Gestión Cultural

www.terciocreciente.com

http://revistaselectronicas.ujaen.es/index.php/RTC
Monográfico Extraordinario I

Julio 2017

Investigación 